\title{
Jogos Virtuais e Educação nas Escolas ${ }^{1}$
}

\author{
Suely SCHERER ${ }^{2}$ \\ Claudia Steffany da SILVA MIRANDA ${ }^{3}$
}

\begin{abstract}
Resumo
O estudo apresentado neste artigo tem por objetivo propor reflexões sobre o uso de jogos virtuais nas escolas, com foco na (re)construção de conceitos de diferentes áreas. O jogo virtual pode ser considerado um importante recurso de aprendizagem na escola, pois possibilita que o aluno vivencie desafios e tenha feedbacks a cada tomada de decisão no jogo. No entanto, discute-se que para que o jogo virtual seja um recurso de aprendizagem na escola, o seu uso deve ser planejado pelo professor para que os alunos aprendam algum conceito ou procedimento, a partir da mediação do professor ao longo do processo. Também é necessário propor ações na escola para discutir as mensagens e contramensagens presentes no contexto do jogo.
\end{abstract}

Palavras-Chave: Jogo Virtual; (Re)construção de conceitos; Escola.

\begin{abstract}
The study presented in this paper aims to propose reflections on the use of virtual games in schools, focusing on the (re) construction of concepts from different areas. The virtual game can be considered an important learning resource in school, because it allows the student to experience challenges and get feedback in decisions making in the virtual game. The virtual game is a resource for learning in school, but your use need to be planned by the teacher, with objective in the learning of some concept and procedure, and, in the analysis of messages present in the context of the game.
\end{abstract}

Keywords: Virtual Games; (Re)construction of concepts; School.

1 Trabalho apresentado à quinta edição da Revista Ação Midiática - Estudos em Comunicação, Sociedade e Cultura, publicação ligada ao Programa de Pós-Graduação em Comunicação, da Universidade Federal do Paraná.

2 Professora e pesquisadora na área de Educação com ênfase em Tecnologias Educacionais e Educação a Distância, atuando principalmente nas seguintes linhas: educação a distância, informática na educação, educação matemática e formação de professores. Possui doutorado em Educação (Currículo) na linha de Tecnologias Educacionais pela Pontifícia Universidade Católica de São Paulo. Atualmente é professora adjunta na Universidade Federal do Mato Grosso do Sul.

3 Mestre em Educação Matemática pelo Programa de Pós-Graduação de Mestrado em Educação Matemática da Universidade Federal do Mato Grosso do Sul (2012). Tem experiência na área de Educação Matemática e tecnologias digitais, com pesquisas relacionadas á temática de jogos virtuais e aprendizagem com uso de computador. Possui experiência em tutoria à distância e atualmente atua como professora na rede estadual de ensino do Mato Grosso do Sul. 


\title{
Introdução
}

Quando se fala em tecnologia, considera-se neste artigo o que afirma Kenski.

\begin{abstract}
Ao conjunto de conhecimentos e princípios científicos que se aplicam ao planejamento, à construção e à utilização de um equipamento em um determinado tipo de atividade nós chamamos de "tecnologia". Para construírem qualquer equipamento - seja uma caneta esferográfica ou um computador -, os homens precisam pesquisar, planejar e criar tecnologias (KENSKI, 2007, p. 18).
\end{abstract}

De acordo com a autora, tecnologia é toda e qualquer invenção do ser humano, que, com o tempo e com as necessidades, vai se aperfeiçoando. O ser humano modifica-a para melhorar as suas relações com o meio ambiente e outros seres humanos.

Neste artigo apresenta-se um estudo sobre as tecnologias digitais que podem favorecer a aprendizagem dos alunos, mais especificamente o computador e os jogos digitais.

Alguns autores (MOITA, 2007; PRENSKY, 2010; KENSKI, 2007) ressaltam que, apesar de estarem sendo usadas por muitos alunos, pouco se faz no sistema educacional para introduzir as tecnologias digitais em seu meio, mudando pouco as estruturas escolares. Segundo Kenski (2007, p. 45): “As tecnologias [...] não provocam ainda alterações radicais na estrutura dos cursos, na articulação entre conteúdos e não mudam as maneiras como os professores trabalham didaticamente com seus alunos".

Integrar o computador na educação requer muito mais do que simplesmente "encher" as escolas de computadores, requer um estudo pedagógico sobre eles. Como afirma Bittar (2010, p. 259), "[...] integrar um novo instrumento em sala de aula implica mudanças pedagógicas, mudanças do ponto de vista da visão de ensino, que devem ser estudadas e consideradas pelos professores".

O uso do computador como toda e qualquer tecnologia digital deve ser bem-estudado para ser integrado no ambiente escolar, analisando seus possíveis malefícios e benefícios. Valente (1998) afirmou que alguns professores dizem que é perder tempo usar o computador na escola, pois consideram que possuem tantos outros problemas na educação e que se preocupar com a utilização dele seria esquecer os problemas maiores como: indisciplina, violência, salário baixo, entre outros.

Valente (1998) também afirmou que muitos professores “[...] batem na mesma tecla", de que o computador substituirá o professor e que, daqui a alguns anos, esse profissional não será mais útil. Estes são professores que têm uma ideia equivocada do uso do computador e se limitam a pensar em uma máquina que transmite informações e em alunos receptores destas; compreendem o ensino como uma transmissão de informação, e, nesse caso, facilmente o professor seria substituído pelas máquinas. O que observamos é que, passados 14 anos dessa publicação do autor, muitos professores ainda continuam pensando da mesma forma.

Por outro lado, Valente (1998) afirmou que existem professores otimistas e que realmente 
acreditam que o computador veio revolucionar, veio para mudar a escola. Mas, será que é essa a melhor posição: ver o computador como o salvador da educação? Tê-lo significa uma educação melhor, com mais qualidade? Temos de continuar refletindo sobre tais questões, pois os dois extremos são preocupantes.

Segundo Prensky (2010), muitos alunos de hoje são os chamados "nativos digitais", crianças que há muito tempo já convivem com o computador, internet, celular, entre outras tecnologias digitais. Essas crianças, segundo o autor, têm muita facilidade em aprender a utilizar tecnologias digitais; elas têm maneiras de se relacionar, pensar e de agir diferentes de nós, que somos "imigrantes digitais".

Para Prensky (2010), os imigrantes digitais, a maioria dos professores e gestores das escolas, pensam de uma maneira diferente, aprendem diferente, agem diferente. Os imigrantes gostam de textos lineares, a aprendizagem acontece sem muitos movimentos e interações. Os nativos digitais gostam de ler sem ter apenas uma ordem a seguir; é ler um pouco aqui, e se algo interessar, "pulam" para "lincar" ali; eles gostam de trabalhar com hipertextos.

Os nativos digitais não querem ser aqueles alunos que passam horas sentados na cadeira lendo um texto ou olhando para o quadro copiando conteúdo. Eles querem autonomia, querem poder questionar e vivenciar o que aprendem, além do que "os nativos preferem imagens aos textos" (PRENSKY, 2010, p. 60).

Segundo estudos realizados por Papert (2008), o computador precisa ser usado na escola para favorecer a construção do conhecimento. Pensando nessa abordagem, e considerando os alunos nativos digitais (PRENSKY, 2010), aos poucos podemos reinventar a escola. Essa reinvenção está relacionada com o fato de os alunos de hoje terem uma maneira diferente da nossa de aprender, como citado anteriormente.

\footnotetext{
Na maior parte do tempo, estão brincando, jogando e interagindo com amigos virtuais. Essas ações podem ser vistas como problemas, mas também como caminhos por onde as escolas podem trazer os estudantes para novas e mais prazerosas formas de aprender (KENSKI, 2007, p. 60).
}

Mas, com tantas mudanças nos meios de comunicação, maneira de agir e principalmente com o avanço da internet e de seus recursos, o que a escola pode fazer ou faz para ajudar as crianças a aprenderem? Este estudo que apresentamos aqui não tem como objetivo propor respostas a essa pergunta, mas incitar a refletir sobre caminhos para mudanças, e um deles é o uso de jogos virtuais nas escolas, com foco na (re)construção de diferentes conceitos.

Quando iniciamos um processo de construção de algum conceito, não conseguimos retirar todas as informações necessárias desse objeto de conhecimento que está sendo abstraído. A cada nova interação com esse objeto, com o objetivo de compreendê-lo, abstraímos novos 
conhecimentos, que são articulados aos conhecimentos anteriores, pois, segundo Becker (1993), sempre existe algo novo a ser construído, a ser aprendido sobre o objeto em questão. Assim, a cada nova interação, o sujeito amplia o seu conhecimento anterior em relação ao objeto, vivenciando o que consideramos ser a (re)construção de conhecimentos ou de conceitos.

Nesse sentido, discute-se neste artigo o uso de jogos virtuais disponíveis nas redes sociais, que pode ser umas das maneiras de favorecer a aprendizagem dos alunos. A referência não está no uso descompromissado de jogos, mas no uso destes com foco na aprendizagem de conceitos, procedimentos e atitudes de diferentes áreas.

No primeiro item deste texto abordam-se algumas questões relacionadas à aprendizagem com uso de computadores, afinal, o uso de jogos virtuais depende do uso de computadores. Na sequência discutem-se pontos positivos e negativos no uso de jogos virtuais, e por fim, discutem-se possibilidades de uso de jogos virtuais na escola.

\section{Aprendizagem e uso de computadores}

Embora muitas tecnologias digitais estejam presentes na maioria das escolas hoje, alguns professores não sabem como usar tais tecnologias para favorecer os processos de aprendizagem de seus alunos. Muitos consideram necessário pensar primeiramente em aprender tudo sobre a tecnologia a ser utilizada, para depois pensá-la como recurso a proporcionar aprendizagem aos alunos. No entanto, segundo Valente (2003, p. 1): "O melhor é quando os conhecimentos técnicos e pedagógicos crescem juntos, simultaneamente, um demandando novas ideias do outro".

O professor deve conhecer a tecnologia que vai utilizar, não necessariamente toda a parte técnica, mas as potencialidades da tecnologia, pois toda aula, seja ela com ou sem tecnologias digitais, deve ter objetivos que favoreçam os processos de aprendizagem. Assim, quando são usadas tecnologias digitais em uma aula, estas devem ser utilizadas para ajudar a atingir esses objetivos. Muitas vezes, não ir para um laboratório de informática pode ser mais produtivo (para aprendizagem do aluno de algum conceito) do que utilizar tecnologias digitais sem o objetivo de aprendizagem. Por exemplo, levar os alunos ao laboratório de informática para jogar, utilizando o jogo pelo jogo, sem intenção de ensino e/ou de aprendizagem, pouco contribui para pensar a educação na escola.

Isto também pode acontecer com um computador conectado à internet. Ele pode nos oferecer muitas informações, e se o aluno apenas navegar ou "pesquisar", sem que ele pense sobre as informações encontradas, e sem que o professor seja o mediador da situação, questionando e orientando o aluno em possíveis aprendizagens, pouco ou nada contribuirá para que o aluno produza conhecimento.

Ter acesso a informações não significa que o aluno irá construir conhecimento, como afirma Valente (2003, p. 4): “[...] o conhecimento é o que cada indivíduo constrói como produto 
do processamento, da interpretação, da compreensão da informação". Ou seja, não basta o professor possibilitar aos alunos a busca de informações, o importante é que os desafie para a reflexão sobre a informação encontrada.

Valente (2003) enfatiza a importância do papel do professor no processo de aprendizagem de alunos ao usarem o computador. Nesse sentido, ao propor o uso de um jogo, ele deve ser planejado e acompanhado pelo professor, com o objetivo de favorecer a aprendizagem do aluno. Deve haver uma intenção para o uso do jogo em aula, ou seja, um objetivo de aprendizagem, que deve ser para além da ação de simplesmente jogar.

No ambiente do jogo virtual, o aluno recebe inúmeras informações, porém, na maioria das vezes, seu objetivo não é pensar sobre o ponto de vista de uma área específica, sobre as informações presentes no jogo, ele simplesmente joga para cumprir o objetivo do jogo (ganhar, passar de fases, entre outros). Cabe ao professor mediar tal situação, oportunizando ao aluno a construção de conhecimentos a partir das informações obtidas no jogo.

Em alguns jogos virtuais "não educativos" ${ }^{4}$ estão presentes conceitos de diferentes áreas, porém, em geral, não são discutidos na escola com os alunos. Estes acabam se aproximando desses conceitos sem muitas vezes compreendê-los, o que consiste em um motivo em potencial para o professor usar o jogo virtual em suas aulas. Para isso, é importante compreender o processo de aprendizagem com o uso do computador. Esse processo pode ser discutido a partir dos estudos realizados por Valente (2005), sobre o ciclo de ações e a espiral de aprendizagem. O ciclo é composto de quatro ações: descrição, execução, reflexão e depuração, conforme Figura 1.

A ação de descrição ocorre quando o sujeito descreve para o computador, por meio de uma linguagem (no caso do jogo, por meio de comandos), uma possível solução para o problema que deseja resolver.

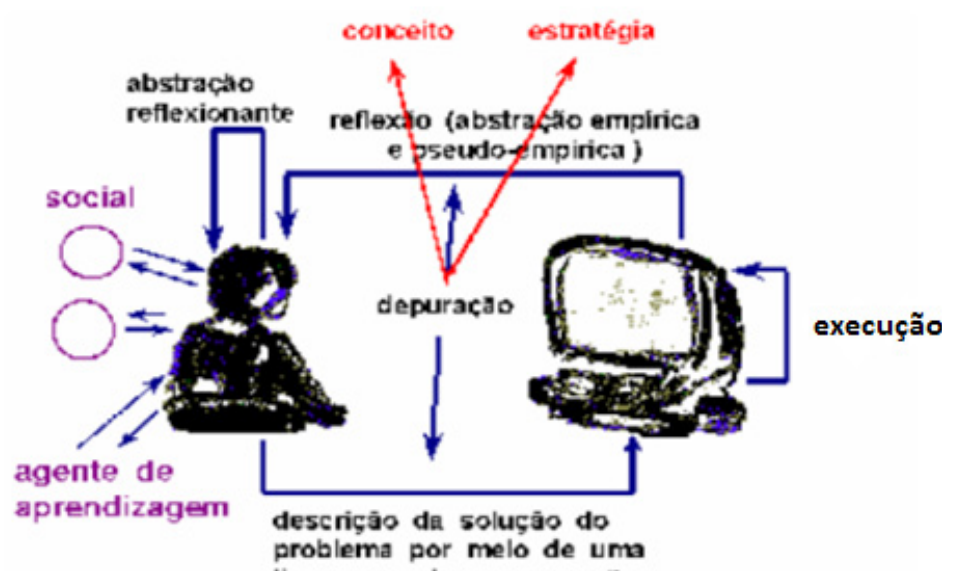

Figura 1 - Ciclo de ações

Fonte: Valente (2005).

4 Neste artigo considera-se como jogos não educativos, aqueles que não foram criados com o objetivo de estarem dentro das escolas, com o objetivo pedagógico; porém, podem ser usados na/para educação. 
A ação de execução é feita exclusivamente pelo computador, isto é, o computador "lêe" a descrição e a executa, apresentando-a graficamente; o que é visto na tela pode ou não ser o que o sujeito deseja.

Ao se deparar com a resposta apresentada na tela, o sujeito pode iniciar a ação de reflexão, que é subdividida em três níveis de abstrações, essenciais para a construção do conhecimento: empírica, pseudoempírica e reflexionante.

A abstração empírica é caracterizada pela retirada, pelo sujeito, de informações do objeto, das experiências físicas; essas características são observáveis, tais como: cor, textura e outras. Segundo Valente (2005), essa abstração ocorre quando o sujeito obtém informações do objeto apresentado, restringindo-se apenas às características observáveis do objeto representado no computador.

Aabstração pseudoempírica ocorre quando o aluno retira propriedades e/ ou características presentes nos objetos, porém não visíveis no objeto, cujas características são impostas ao objeto pelo aluno. Ou seja, o sujeito enriquece o objeto com informações que não são próprias deste, mas das coordenações mentais do sujeito.

$\mathrm{Na}$ abstração reflexionante, o sujeito não depende mais da representação do objeto, pois ela é mental, endógena ao sujeito, havendo alguma mudança na sua compreensão ou construção de conceitos. Nessa abstração há uma coordenação, pelo sujeito, das ações realizadas por ele sobre o objeto.

A abstração empírica é a mais simples, permitindo ao aprendiz extrair informações do objeto ou das ações sobre o objeto. [...] A abstração pseudo-empírica permite ao aprendiz deduzir algum conhecimento da sua ação ou do objeto. [...] Mudanças conceituais e construção de novos conhecimentos são frutos da abstração reflexionante (VALENTE, 2005, p. 67-68).

Ao realizar possíveis reflexões sobre a resposta executada pelo computador, o aluno pode depurar essa resposta. A depuração consiste na melhora, no refinamento da descrição enviada ao computador, no intuito de realizar a tarefa.

Por meio da depuração, o sujeito pode rever conceitos e/ou estratégias utilizadas para resolver determinado problema, corrigir erros.

Achar e corrigir erros (ou bugs na linguagem computacional) constitui uma oportunidade única para o aprendiz entender o que está fazendo e pensando. Além disso, a depuração pode criar oportunidades para o professor ou agente de aprendizagem trabalhar em um nível metacognitivo como o aprender-a-aprender, o pensar-sobre-o-pensar (VALENTE, 2005, p. 75).

Ao pensar no jogo virtual, a depuração é usada para eliminar o erro, melhorar estratégias e, por meio de novas descrições, melhorar o desempenho. O ciclo de ações no 
jogo inicia quando o aluno, ao tomar alguma decisão em um jogo virtual, envia comandos para o computador executar, os quais podem ou não reproduzir o que o aluno deseja. No caso da reprodução feita pelo computador não ser adequada ao projeto do aluno, este reflete sobre o novo cenário presente no jogo e toma uma nova decisão, enviando-a ao computador, recomeçando um novo ciclo a cada decisão depurada, até atingir o resultado esperado no jogo ou até encontrar outro foco de interesse.

Toda vez que o aluno faz a depuração de alguma resposta executada pelo computador, ele agrega à nova descrição (fruto da depuração da resposta anterior) novos conhecimentos, podendo realizar nova descrição (esta já com os conhecimentos agregados da depuração anterior), que o computador executará e o aluno refletirá novamente, podendo realizar nova depuração. A cada depuração, resultam novos conhecimentos. Logo, percebe-se que o que se repete no ciclo de ações apresentado por Valente (2005) são as ações, pois o conhecimento, a cada depuração vai se modificando, em formato de espiral - a espiral de aprendizagem.

Valente (2005) distingue as ações (que ocorrem em um ciclo) da espiral de aprendizagem.

Mesmo no caso do erro (ou bug, como é usado em computação) o aprendiz está fazendo progresso do ponto de vista do seu pensamento, pois ele tem mais dados para realizar outras tentativas. O produto pode até ficar pior, mas o nível de conhecimento cresceu e continua crescendo na forma de uma espiral [...] (VALENTE, 2005, p.7).

O ciclo de ações e a espiral de aprendizagem ocorrem simultaneamente, ou seja, só acontece um se o outro ocorrer.

No entanto, para que o sujeito seja capaz de completar o ciclo, o professor tem um papel fundamental, o de agente de aprendizagem, auxiliando o sujeito a manter o ciclo de ações, para que ocorra a espiral de aprendizagem.

No ciclo de ações apresentado por Valente (2005), existem alguns fatores que influenciam, diretamente ou não, o sujeito nas suas ações. É o caso do meio social. O meio social do aluno que está jogando conectado à internet pode englobar outras pessoas, jogadores de outros ou do mesmo jogo, bem como aquelas que podem estar presencialmente com ele.

Como exemplo, imaginemos uma criança jogando em rede pela internet. Essa criança pode estar fisicamente só, mas virtualmente não, pois conectada pode estar se comunicando com muitas pessoas. O meio social desse aluno é muito mais complexo do que daquele sujeito sozinho na frente do computador (offline). As intervenções desse meio social podem contribuir com o processo de aprendizagem dos alunos, contribuindo para que a cada tomada de decisão da criança, e a cada proposta de comando enviada ao computador, um novo ciclo comece e uma nova aprendizagem aconteça. 
Neste item foram discutidos alguns elementos relacionados ao uso de computadores para favorecer a aprendizagem dos alunos na escola, na sequência, discutem-se alguns aspectos positivos e negativos no uso de jogos virtuais nas escolas.

\section{Aspectos positivos e negativos dos jogos virtuais}

Ao investigar sobre o uso dos jogos é importante conhecer os dois "lados da moeda", ou seja, os dois lados do uso dos jogos virtuais. Neste artigo se investe no lado positivo do jogo, por exemplo, a sua contribuição para a aprendizagem dos alunos. Na escola, pode-se redimensionar o sentido da aprendizagem com os jogos, pois informalmente sempre se aprende jogando. Pode-se comparar essa afirmação com os estudos de Fischer (2001) sobre o uso da televisão, quando afirma que assistindo a programas por ela se aprende, seja uma estratégia, uma brincadeira, o que nos importa é: o que se aprende consciente ou inconsciente? Pois são várias informações, mensagens diretas ou subliminares que chegam ao telespectador. O mesmo acontece com o usuário de um jogo virtual.

Algumas pesquisas (PRENSKY, 2010; ALVES, 2004; HAGUENAUER et al., 2007) discutem o uso de jogos pelo fato de serem uma atividade lúdica, pela possibilidade da catarse ${ }^{5}$. As pessoas jogam, são livres para jogar, sabem que ali estão em um momento de diversão, embora joguem com muita seriedade.

O jogo ativa e desenvolve as estruturas cognitivas do cérebro, facilitando o desenvolvimento de novas habilidades como observar e identificar, comparar e classificar, conceituar, relacionar e inferir, além de desenvolver a criatividade, perseverança e sociabilidade (HAGUENAUER et al., 2007, p. 3).

As crianças e os adolescentes jogam, na maioria das vezes, com um único objetivo, o de vencer. Jogam respeitando regras, o que, segundo Alves (2004), podem ajudá-los a conviver na sociedade, pois aprendem a viver em grupo, a ter algumas limitações. Além disso, a autora afirma que o jogo pode contribuir para o desenvolvimento cognitivo dos usuários.

$\mathrm{O}$ uso dos jogos online aumenta o campo de informações que são apresentados às crianças e aos adolescentes, ao jogador, podendo cada vez mais auxiliá-los na exploração e na compreensão de novos conceitos.

O computador e a internet ampliam a representação da realidade, abrindo possibilidades para um novo enfoque educacional baseado em jogos, permitindo a exploração de diversos recursos multimídia. Sua utilização modifica a dinâmica do ensino, as estratégias e o comportamento de alunos e professores. A possibilidade de simulação que os jogos de computador e internet oferecem, acentuam três características básicas dos jogos em geral: a fantasia, a curiosidade, e o desafio (HAGUENAUER et al., 2007, p. 6).

5 Extravasamento, ficar livre dos problemas, lidar com a raiva em um lugar não real. 
Os jogos, de modo geral, não são criados com o objetivo de ensinar algo na escola, ou para que a criança aprenda algum conceito (lado pedagógico). Eles são criados para que haja a diversão e para deixar o usuário livre para se divertir.

Nesse sentido, discute-se aqui o uso do jogo de maneira que não tire suas características fundamentais (ludicidade, liberdade de escolha, regras do jogo, criatividade, interatividade, hipertextualidade), mas que para o professor seja um recurso que contribua para o processo de aprendizagem de conceitos específicos.

Além das características positivas, aqui citadas, algumas pesquisas mostram o lado negativo do jogo. Por exemplo, a violência contida em alguns, se reproduzida na vida real, é um grande risco à sociedade.

Por isso, as mensagens de violência devem ser trabalhadas no dia a dia dos alunos, afinal, é fato que eles jogam online, e a maioria dos jogos explora cenários de violência. Mas, o que os alunos estão fazendo com as mensagens contidas nos jogos? Será que eles tomam consciência das informações contidas nas mensagens? Estas são questões que nos levam a investigar as possibilidades de usar jogos virtuais nas escolas, atentando para a necessidade de os alunos tomarem consciência de possíveis influências do jogo em sua vida.

Quando se menciona que os jogos virtuais podem influenciar no comportamento das crianças, é importante lembrar que não são apenas eles os causadores de alterações comportamentais (ALVES, 2004). Desse modo, o que a escola está fazendo para mudar essa realidade? Apenas criticar o uso de jogos, ou jogar por jogar, nada ou pouco ajudará.

Prensky (2010) afirma que muitas mensagens são transmitidas para as crianças pela internet, e que os nativos digitais estão hoje muito mais propícios a vários tipos de mensagens, sejam elas boas ou ruins, mas que essas mensagens não trarão efeitos significativos se esses alunos receberem contramensagens, que negam o conteúdo da mensagem emitida. Essas contramensagens podem ser emitidas pela sociedade, pela escola, pelos pais e/ou pela mídia. Portanto, não são apenas os jogos virtuais que tornam crianças violentas, e, a partir de contramensagens, elas podem questionar o conteúdo delas, de forma consciente ou inconsciente.

A violência presente nos jogos, uma característica que, por vezes, é considerada negativa, em alguns estudos é trabalhada como não tão negativa. Jones (2004) discute a violência como brincadeira do "faz de conta", afirmando que

Crianças têm a necessidade de se sentir fortes. Precisam se sentir poderosas perante um mundo assustador e incontrolável. Super-heróis, guerreiros de games, rappers e atiradores de filmes são símbolos de força. Quando fingem ser um desses personagens, as crianças sentem-se fortes (JONES, 2004, p. 12).

Quantos de nós, pais, professores, vimos crianças brincarem de matar monstros, de matar seus próprios coleguinhas, pais, primos e sentirem-se felizes depois de observarem que 
acertaram seus alvos. As crianças utilizam o faz de conta para exaltar o que lhes incomoda no real. Elas brincam de brigar, sabendo que tudo não passa de uma simples brincadeira, assim como os jogos violentos, no qual o principal objetivo é matar seus adversários, elas o fazem com o maior prazer, e é essa violência excessiva que as atrai nesses jogos e brincadeiras.

As crianças ao jogarem sabem que ali estão apenas brincando e que nada acontecerá com elas na vida real, se matarem alguém no jogo, essa pessoa pode reviver, sabem que não sofrerão consequências maiores do que no máximo perder ou ganhar.

As crianças querem sentir que podem vencer, gostam da disputa, do poder, de ter coragem e aprendem a conviver com diferentes tipos de pessoas.

Outro aspecto negativo dos jogos são os vícios. Sabemos que muitas coisas são viciantes, mas, uma delas que preocupam os pais são os jogos. Muitas crianças e adolescentes são praticamente dependentes de jogos virtuais, da internet. Sabe-se que tudo requer limites e que pode ser diferente desde que os pais e professores sejam capazes de limitar a frequência do uso dos jogos pelas crianças e adolescentes.

Limitar significa impor limites e não proibir, pois as crianças têm acesso a esses jogos em muitos outros lugares. Daí a importância de usá-los na escola, pois é a possibilidade de estudar as mensagens neles contidas, melhorar estratégias, trabalhar com conceitos em contextos próprios do jogo, orientados pelo professor.

Nas escolas, os alunos devem jogar, mas sabendo sobre o que estão discutindo, sobre o que estão vivendo, eles devem ser críticos, devem saber pensar sobre o que estão fazendo, e não jogar sem limites, sem orientação de um profissional da área de educação, sem refletir sobre conteúdos, estratégias.

$\mathrm{Na}$ escola, ao usar jogos virtuais nas aulas, deve-se focar em alguns papéis, como o do professor, que tem de conhecer os jogos que os alunos estarão jogando, para que possa planejar ações de estudos, sem perder de vista o prazer pelo jogo.

Um dos objetivos do professor ao usar jogos virtuais na escola é possibilitar a reflexão dos alunos sobre as mensagens; que compreendam conceitos e estratégias importantes para pensar e vivenciar melhor aquele jogo específico e outros jogos e situações. Nesse sentido, é importante discutir o uso do jogo como uma possibilidade de (re)educação nas escolas, questão abordada no próximo item.

\section{O uso de jogos virtuais na escola: possibilidade de uma (re)educação?}

O uso de jogos está presente no cotidiano de muitos alunos e distante de muitas escolas. Por isso, há necessidade de se discutir uma (re)educação na escola a partir do uso de jogos virtuais. Essa (re)educação constitui um processo de integração da linguagem digital às práticas educativas na escola. 
A escola pouco trabalha as diferentes linguagens que mobilizam alunos para a aprendizagem, diferente dos produtores de jogos virtuais, os tão famosos games.

O mercado dos games vem se propondo a mudar, mesmo que, em grande parte, pela pressão que sofre, mas parece revelar-se mais competente do que a escola para ajudar a entender que, se não tocarmos profundamente nas motivações internas das pessoas e grupos de interesses, não teremos sucesso em nossas propostas de troca/produção de saberes humanamente gratificantes/ relevantes (MOITA, 2007, p. 30).

Por concluírem que nem todos os tipos de jogos atraem meninos e meninas, os produtores dos jogos mudam cada vez mais seus jogos, evoluindo, e em cada época há um novo. Os jogos de hoje também mudaram, conforme pede a sociedade e os "nativos digitais" (PRENSKY, 2010).

As crianças adquirem um maior nível de aprendizagem, porque o conhecimento obtido nos games pode ser aplicado imediatamente. Além disso, os games têm a vantagem de permitir passar as informações de uma maneira mais divertida e interativa (GEE apud MOITA, 2007, p. 39).

Muitas vezes as crianças veem um conteúdo na escola e depois somente em suas lições de casa. Esse conteúdo escolar dificilmente é usado para aprender ou compreender algo em outros espaços e ações, como o de um jogo virtual.

Nos jogos virtuais, as crianças e os adolescentes utilizam vários conceitos, por exemplo, conceitos de matemática que aparecem implícitos aos jogos, e muitas vezes não se dão conta do que estão utilizando. Eles precisam de um mediador, de alguém que ajude a refletir sobre as mensagens e informações dos jogos, sobre as estratégias, sobre os conceitos que permeiam o jogo, ajudando a institucionalizá-los. Na escola, esse alguém pode ser o professor. Mas, para que isso ocorra, a escola também deverá estar aberta a mudanças, afinal:

Se um jogo eletrônico, com intuitos educativos, for divertido, a atenção dos jogadores pode ser canalizada, durante bastante tempo, para aprendizagem de conteúdos diversos. Além disso, os jovens jogadores terão necessariamente que tomar rápidas decisões com frequência, recebendo feedback imediato acerca dessa tomada de decisão (GROS apud MOITA, 2007, p. 41).

O feedback ${ }^{6}$ é algo essencial não somente nos jogos, mas também em softwares matemáticos, pois essa resposta imediata à ação do aluno faz com que ele veja as consequências de sua ação, podendo ou não repensá-la. Moita (2007) reforça que as crianças aprendem conforme seus níveis de compreensão, e que elas adoram desafios, sendo este um dos motivos que as atraem nos jogos virtuais. Segundo Greenfield (1988, p.103), “[...] uma das características mais gerais dos videogames é, acredito, sua contribuição importante para o potencial de aprendizagem. 6 Feedback é o ato de fornecer uma resposta ou um comentário sobre a ação do aluno. 
Quase todos os jogos apresentam níveis diferentes, de acordo com a habilidade do jogador".

Essa questão de desafios é muito complexa, pois, o que pode ser desafio para um aluno, pode não ser para outro, além de ser difícil para um professor organizar situações (com diferentes níveis de dificuldades) que envolvam a maioria de seus alunos.

Moita (2007) cita que os jogos virtuais podem ajudar no convívio com a sociedade. Quando eles são em equipes, ainda contribuem para o convívio em grupo, para uma aprendizagem colaborativa. É claro que o uso do jogo na escola não deixa de ser uma diversão, mas é uma diversão acompanhada por um professor, com o objetivo de aprendizagem. Assim, o jogo virtual pode ser compreendido como recurso pedagógico para o professor e entretenimento para as crianças.

Segundo Prensky (2010), as crianças aprendem por hipertextos, e os jogos são uma rede interminável deles, contribuindo assim para a aprendizagem das crianças consideradas nativos digitais. Os jogos online jogados em grupos podem ajudá-los a conviver com pessoas diferentes e que vivem em lugares diferentes. Essas pessoas interagem, trocam informações sobre suas culturas, e essas interações colaboram ainda mais para o desenvolvimento psicológico dos jogadores.

As crianças, nativos digitais, estão hoje em contato com imagens, sons e formas, transformando-se em crianças ativas, porém isso não significa necessariamente que têm aprendizagens ativas. Segundo Moita (2007, p. 76), “[...] numa aprendizagem ativa estão envolvidas três ações: experimentar o mundo de formas novas, formar afiliações novas e preparar aprendizagens futuras".

As crianças não necessitam apenas ser ativas, precisam ser críticas, saber trabalhar com suas criatividades, aprender a usar de diferentes formas as imagens e os conteúdos que estão nos jogos ou em outros espaços de redes sociais.

O contato dos "nativos digitais" com essas várias informações está cada vez mais abundante, porém não tem quem os ajude a formalizar e criticar o que estão tendo acesso, vivenciando. A escola não acompanha essa demanda e o modo de aprender dos nativos digitais.

Para Moita (2007), alguns pesquisadores concordam que há necessidade de uma (re) educação no sistema educacional,

Gee (2004) e Castells (2001) parecem estar de acordo e alertam para a necessidade de mudança nos espaços e processos de educação, na concepção e no desenvolvimento de novas abordagens para realização de aprendizagens on-line (MOITA, 2007, p.76).

Não basta ter essa grande massa de estudantes aprendendo coisas online, eles precisam de alguém que possa ajudar a institucionalizar conceitos, orientar aprendizagens, alguém que os ajudem a serem mais críticos e oportunizem a criarem e compartilhar mais informações, a partir 
das informações que têm acesso e consomem.

Apesar de o jogo virtual ser, segundo Moita (2007), um ambiente que pode proporcionar uma partilha de informações, estas só farão sentido aos alunos se forem críticos com elas e as transformarem em conhecimentos. Para que isso ocorra, é necessário o auxílio de um profissional preparado a ajudá-los: o professor.

Saber o que os alunos jogam e o porquê de estarem jogando pode ajudar os professores a entender o que os motiva tanto a jogarem, e principalmente pode auxiliar os professores a mudarem seu modo de dar aulas, orientando os alunos em suas aprendizagens, além de aprenderem com eles.

Moita (2007, p. 87) conclui a partir de observações de alguns jovens jogadores que "eles têm formas diferenciadas de ver o que aprendem com os games". Muitas vezes não estabelecem relações com que é lhes ensinado na escola.

Pode-se verificar uma grande diferença entre os ambientes dos jogos virtuais e o ambiente da escola.

\footnotetext{
Encontra-se aí uma grande diferença em relação à escola, onde, apesar das mudanças, ainda é possível se observar um comportamento concentrado no pólo de emissão - o professor - detentor de um conhecimento pronto e acabado que repassa aos alunos, os quais, enquanto receptores passivos ou quase passivos, apropriam-se dos conteúdos, obedecendo a uma disciplina, a uma ordem preestabelecida à qual não podem acrescentar quase nada da sua história de vida, de seu cotidiano, em que não existe espaço para sua criatividade (MOITA, 2007, p. 92).
}

Segundo Moita (2007), nos jogos virtuais as crianças não são passivas, são extremamente ativas, concordam ou não com seus resultados, interagem com seus companheiros e adversários. No ambiente do jogo, elas criticam seus resultados, criam e recriam, e estão em constante aprendizagem.

Ser submisso às ideias dos professores, tornar o professor como o ponto inatingível, como o detentor de todo o saber, já não caracteriza as relações que os alunos vivem em seu cotidiano. Eles querem um ambiente hipertextual, querem aprender, mas que essa aprendizagem seja advinda de muitas discussões; eles querem ser críticos e querem expor suas necessidades e suas angústias; querem um ambiente mais colaborativo.

Para que os jogos sejam integrados ao ambiente escolar há uma necessidade de mudança na cultura escolar, é preciso um currículo mais flexível, assim como professores e gestores mais abertos a discussões e dispostos a aprenderem com os alunos.

No ambiente do jogo virtual existem várias imagens, sons, interatividade e esse contexto é muito mais amplo e complexo que muitos contextos escolares. Moita (2007) afirma que, com esse novo contexto, deve-se preparar um currículo que o comporte, deve-se (re)educar a cultura escolar. 
É importante investir em uma cultura em que os alunos são ativos, colocam suas experiências, aprendem a ser críticos e a expor suas necessidades. Uma cultura que invista em um currículo escolar flexível, segundo Moita (2007, p. 106), um currículo “[...] não como produto, estanque, mas como um processo, em incessante agitação e conforme a multiplicidade que é a nossa vida".

Os jogos compõem um ambiente favorável para a aprendizagem na escola. Mas, ele se torna favorável desde que o professor estude o jogo e planeje aulas com objetivos focados na aprendizagem, respeitando as características do jogo. O objetivo não é "formatar" o jogo para atividades na escola, é jogar, e a essa ação, integrar a de se debruçar sobre o jogo, para explorar/ estudar informações e o contexto que o constitui, sem esgotar possibilidades.

O professor deve ter consciência de que a cada momento pode surgir um novo conhecimento a ser explorado, anunciado por ações do aluno ou do professor, pela possibilidade de investigar diferentes estratégias e conhecimentos mobilizados pelos alunos.

\section{Algumas considerações}

Os jogos virtuais estão em constantes atualizações em função das exigências de seus usuários. O mesmo não acontece na escola, pois os alunos exigem novas ações, novas propostas, mais articuladas às características dos nativos digitais, mas, pouco se observa de atualizações de metodologias e recursos na sala de aula. Neste sentido, muito há por propor e experienciar, e, o uso de jogos virtuais na escola é uma proposta possível e que merece ainda muitos estudos.

As escolas devem estar preparadas para o uso do jogo virtual, devem oportunizar a vivência de um currículo mais flexível, pois o uso dos jogos virtuais requer flexibilidade de ações no tempo e sequência de aula do professor, bem como do currículo prescrito. Ou seja, a sequência de conteúdos, um dos elementos do currículo prescrito, nem sempre poderá ser posta em ação conforme o que foi prescrito, sendo redimensionado na ação com os alunos, ao explorarem jogos virtuais.

Alguns professores têm receio em utilizar jogos virtuais pelo excesso de violência contida em alguns deles, porém como foi explicitado neste artigo, existem vários pontos positivos no uso dos jogos, e é importante focar nestes pontos, e propor ações de reflexão sobre contextos violentos. A escola é espaço educativo para o debate, reflexões e estudos sobre diferentes contextos e temas, inclusive o tema de violência presente nos jogos virtuais.

Ao estudar conteúdos presentes nos contextos dos jogos e institucionalizá-los, estamos contribuindo, como educadores, para que os alunos, não só obtenham melhores resultados e desempenho nos jogos, mas, e principalmente, para que tomem consciência dos conceitos necessários para agir em cada etapa do jogo, bem como das mensagens emitidas por estes, agindo de forma consciente e fundamentada. 
Este estudo evidenciou que é possível integrar jogos virtuais na escola. E, que o papel do professor, desde o momento do planejamento até a avaliação da aprendizagem de uma aula, com uso de jogo virtual, é o de desafiar e orientar o aluno em suas aprendizagens.

\section{Referências}

ALVES, L. R. G. Game over: Jogos e violência. 2004. Tese (Doutorado em Educação) Universidade Federal da Bahia, Salvador, 2004.

BECKER, F. Ensino e Construção do Conhecimento: o Processo de Abstração Reflexionante. Educação e Realidade. Porto Alegre, v.18, n.01, p. 43 -52, 1993.

BITTAR, M. A Escolha do software educacional e a proposta didática do professor: Estudo de alguns exemplos em matemática. In: BELINE, Willian; COSTA, Nielce Meneguelo Lobo Da. (Org.). Educação Matemática, Tecnologia e Formação de Professores: Algumas Reflexões. Campo Mourão: FECILCAM, 2010. p. 253-285.

FISCHER, R. M. B. Televisão \& Educação: Fruir e pensar a TV. Belo Horizonte: Autêntica, 2001.

GREENFIELD, P. M. O desenvolvimento do raciocínio na era da eletrônica: os efeitos da TV, computadores e vídeo-games. São Paulo: Summus, 1988.

HAGUENAUER, C. J. et al. Uso de Jogos na Educação Online: a Experiência do LATEC/ UFRJ. Revista Educa online, UFRJ, v. 1, n. 1, p.1-14, jan/abr, 2007.

JONES, G. Brincando de Matar Monstros: por que as crianças precisam de fantasia, videogames e violência de faz-de-conta. São Paulo: Conrad Editora do Brasil, 2004.

KENSKI, V. M. Educação e Tecnologia: O novo ritmo da informação. Campinas, SP: Papirus, 2007.

MOITA, F. M. G. S. C. Game On: jogos eletrônicos na escola e na vida da geração @. São Paulo: Alínea, 2007.

PAPERT, S. A Máquina da Criança: repensando a escola na era da informática. 2 ed. Porto Alegre: Artmed, 2008.

PRENSKY, M. Não me atrapalhe, mãe - Eu estou aprendendo: como os vídeos games estão preparando nossos filhos para o sucesso no século XXI- e como você pode ajudar!. Tradução por Lívia Bergo. São Paulo: Phorte, 2010.

VALENTE, J. A. Espiral da espiral de aprendizagem: o processo de compreensão do papel das tecnologias de informação e comunicação na educação. Tese (Livre- Docência), Universidade estadual de Campinas, São Paulo, 2005. 
Pesquisa, comunicação e aprendizagem com o computador. Série "Pedagogia de Projetos e Integração de Mídias" - Programa Salto para o Futuro, setembro, 2003. Disponível em: <http://cmapspublic.ihmc.us/rid=1HXFXQKSB-23XMNVQ-M9/VALENTE_2005.pdf>. Acesso em: 22 maio 2012.

Por que o computador na educação. In: VALENTE, J. A. (Org.). Computadores e conhecimento: repensando a educação. 2 ed. CAMPINAS: Gráfica Unicamp, 1998, p. 29-53. 